Chronic Obstructive Pulmonary Diseases: Journal of the COPD Foundation

\author{
Original Research
}

\title{
Nebulized Versus Dry Powder Long-Acting Muscarinic Antagonist Bronchodilators in Patients With COPD and Suboptimal Peak Inspiratory Flow Rate
}

Donald A. Mahler, MD ${ }^{1}$ Jill A. Ohar, $\mathrm{MD}^{2}$ Chris N. Barnes, $\mathrm{PhD}^{3}$ Edmund J. Moran, $\mathrm{PhD}^{3}$ Srikanth Pendyala, $\mathrm{MD}^{3}$ Glenn D. Crater, $\mathrm{MD}^{3}$

\section{Abstract}

Background: Patients with chronic obstructive pulmonary disease (COPD) and suboptimal peak inspiratory flow rate (sPIFR) may not benefit optimally from dry powder inhalers (DPI) because of inadequate inspiratory flow. Nebulized bronchodilators may provide a better alternative. We compared bronchodilation with the longacting muscarinic antagonist (LAMA) revefenacin for nebulization versus the DPI LAMA tiotropium, in patients with COPD and sPIFR (<60 L/min against the resistance of Diskus ${ }^{\circledR}$ ).

Methods: This was a randomized, double-blind, double-dummy, 28-day Phase 3b study in patients with COPD enrolled based on sPIFR. The primary endpoint was trough forced expiratory volume in 1 second (FEV $V_{1}$ on $D a y$ 29 for revefenacin for nebulization versus tiotropium HandiHaler ${ }^{\circledR}$ DPI.

Results: We enrolled 206 patients with mean (standard deviation) age, 65 (8) years; percent predicted FEV 37 (16)\%; PIFR, 45 (12) L/min. In the intent-to-treat (ITT) population, revefenacin improved trough FEV from baseline; however, the difference versus tiotropium was not significant (least squares [LS] mean difference [standard error], 17.0 [22.4] $\mathrm{mL}, P=0.4461)$. In a prespecified analysis of patients with $\mathrm{FEV} \mathrm{F}_{1}<50 \%$ predicted, revefenacin produced an LS mean difference (95\% confidence interval [CI]), 49.1 (6.3-91.9) $\mathrm{mL}$ in trough FEV 1 and 103.5 (7.7-199.3) $\mathrm{mL}$ in forced vital capacity versus tiotropium. Revefenacin produced $>100 \mathrm{~mL}$ increase in $\mathrm{FEV}_{1}$ in $41.6 \%$ versus $34.4 \%$ of patients with tiotropium in ITT and $41.4 \%$ versus $25.7 \%$ of patients in $\mathrm{FEV}_{1}$ $<50 \%$ predicted populations.

Conclusions: Revefenacin did not produce significant improvements in FEV 1 versus tiotropium in the ITT population, but increased trough $\mathrm{FEV}_{1}$ in patients with $\mathrm{FEV}_{1}<50 \%$ predicted and sPIFR.

Clinical Trial Registration (www.Clinicaltrials.gov): Study 0149 (NCT03095456)

Abbreviations: chronic obstructive pulmonary disease, COPD; suboptimal peak inspiratory flow rate, sPIFR; dry powder inhaler, DPI; long-acting muscarinic antagonist, LAMA; forced expiratory volume in 1 second, FEV $\mathbf{1}$; intent-to-treat, ITT; least squares, LS; confidence interval, CI; Global initiative for chronic Obstructive Lung Disease, GOLD; long-acting beta2-agonists, LABAs; forced vital capacity, FVC; inspiratory capacity, IC; adverse event, AE; standard deviation, SD; analysis of covariance, ANCOVA; optimal PIFR, oPIFR; tiotropium, TIO; revefenacin, REV; modified Medical Research Council, mMRC

Funding Support: This study was funded by Theravance Biopharma, Ireland Limited Inc. (Dublin, Ireland). Mylan Inc., (Canonsburg, Pennsylvania) and Theravance Biopharma US, Inc., (South San Francisco, California) funded medical writing support.

Date of Acceptance: September 13, 2019

Citation: Mahler DA, Ohar JA, Barnes CN, Moran EJ, Pendyala S, Crater GD. Nebulized versus dry powder long-acting muscarinic antagonist bronchodilators in patients with COPD and suboptimal peak inspiratory flow rate. Chronic Obstr Pulm Dis. 2019;6(4):321331. doi: https://doi.org/10.15326/jcopdf.6.4.2019.0137 
1 Geisel School of Medicine at Dartmouth, Hanover, New Hampshire and Respiratory Services, Valley Regional Hospital, Claremont, New Hampshire

2 Wake Forest University Medical Center, Winston-Salem, North Carolina

3 Theravance Biopharma US, Inc., South San Francisco, California

Address correspondence to:

Glenn Crater, MD

Phone: 650-808-4078

Email: gcrater@theravance.com

\section{Keywords:}

tiotropium; long-acting muscarinic antagonist; peak inspiratory flow rate; nebulizers; dry powder inhalers

\section{Note: Data from this study were previously presented at the CHEST Annual Meeting, October 6-10, 2018, San Antonio, Texas}

\section{Introduction}

The Global initiative for chronic Obstructive Lung Disease (GOLD) strategy recommends inhaled bronchodilators including long-acting muscarinic antagonist (LAMAs) or long-acting beta2-agonists (LABAs) as maintenance treatment for patients with chronic obstructive pulmonary disease (COPD). ${ }^{1}$ Dry powder inhalers (DPIs) are one of the most frequently prescribed inhalation devices. ${ }^{2}$ However, for effective DPI use, patients must generate enough inspiratory force to overcome the internal resistance of the device to de-aggregate the powdered drug from its carrier into fine particles small enough for lung deposition. ${ }^{3}$ Results from in vitro and in vivo studies have demonstrated that a peak inspiratory flow rate (PIFR) $\geq 60 \mathrm{~L} / \mathrm{min}$ against the internal resistance of an inhaler (e.g., Diskus ${ }^{\circledR}$, GlaxoSmithKline) is optimal for effective DPI use. ${ }^{4-6}$ Because of lung hyperinflation, hypoxemia, and/or muscle wasting, many patients with COPD are unable to generate sufficient inspiratory force to use a DPI effectively. ${ }^{7}$ Suboptimal PIFR ([sPIFR]; < 60 L/ min) has been observed in $19 \%$ to $78 \%$ of outpatients with $\mathrm{COPD},{ }^{6-9}$ suggesting that many patients with COPD may not be able to derive full benefit from DPIs.

We hypothesized that patients with SPIFR may achieve greater improvements in lung function with nebulized bronchodilator therapy than a similar dry powder bronchodilator. We compared the bronchodilation effect of the once-daily LAMA revefenacin inhalation solution via standard jet nebulizer with that of dry powder tiotropium delivered using HandiHaler ${ }^{\circledR}$ in patients with COPD and PIFR $<60 \mathrm{~L} / \mathrm{min}$ against the simulated resistance of the Diskus.

\section{Methods}

\section{Study Design and Conduct}

This was a Phase $3 \mathrm{~b}$ randomized, double-blind, double-dummy, active-comparator, parallel-group, 28-day multicenter study (NCT03095456. See online supplement for study design). It was conducted per the principles of the International Council on Harmonisation of Technical Requirements for Pharmaceuticals for Human Use Guideline for Good Clinical Practice, ${ }^{10}$ and the code of ethics of the World Medical Association's Declaration of Helsinki. ${ }^{11}$ All patients provided written informed consent. The protocol was approved by an institutional review board (Quorum Review IRB, 1501 Fourth Avenue, Suite 800, Seattle, Washington, 98101 [review file no. 32313]).

\section{Patients and Treatments}

We enrolled patients aged $\geq 40$ years with moderate to very severe COPD and PIFR $<60 \mathrm{~L} / \mathrm{min}$ against the resistance of Diskus. Other key eligibility criteria included a smoking history of $\geq 10$ pack years, postipratropium forced expiratory volume in 1 second $\left(F E V_{1}\right) /$ forced vital capacity $(F V C)$ ratio $<0.7$, postipratropium predicted $\mathrm{FEV}_{1}<80 \%$, and screening $\mathrm{FEV}_{1}>400 \mathrm{~mL}$.

Key exclusion criteria included any chronic pulmonary condition other than COPD, including asthma, any medical condition that could preclude inhaled anticholinergics use, COPD hospitalization within 8 weeks of screening, and systemic corticosteroid or antibiotic use for respiratory tract infections within 8 weeks of screening. Patients with concurrent disease or condition, such as hepatic impairment, that in the opinion of the investigator, would interfere with study participation or confound the evaluation of safety and tolerability of the study drug were excluded. Patients were permitted to continue concurrent LABA or inhaled corticosteroid/ LABA therapy.

Patients were randomized (1:1) in a double-blind manner to receive revefenacin $175 \mu \mathrm{g}$ inhalation solution once daily via Pari LC ${ }^{\circledR}$ Sprint jet nebulizer 
(Pari Respiratory Equipment, Inc.) or active-comparator tiotropium $18 \mu \mathrm{g}$ dry powder once daily via HandiHaler device (see Online Supplement for randomization details). Blinding of the study drugs was maintained by the double-dummy design. Revefenacin and its matched placebo were supplied as solutions in sealed plastic vials. Tiotropium was blinded, as described previously, ${ }^{12}$ using a color-matched placebo capsule and a foil overlay masking the placebo package and the commercial blister packing of tiotropium.

\section{Endpoints}

The primary endpoint was change from baseline in trough $\mathrm{FEV}_{1}$ at Day 29. Due to the expected enrollment of patients with mild airflow obstruction, a prespecified subgroup analysis based on airflow obstruction severity-including a subgroup with postbronchodilator $\mathrm{FEV}_{1}<50 \%$ predicted-was planned to compare efficacy in patients with severe to very severe disease. Key secondary efficacy endpoints were the effect of revefenacin versus tiotropium on trough FVC and inspiratory capacity (IC) at Day 29 and peak FEV 1 and FVC at Day 29 (0-4 hours).

A post hoc analysis was performed to examine the effect of sPIFR levels on raw change from baseline in trough FEV 1 by dividing sPIFR into quintiles (<33 L/ $\min , \geq 33$ to $<45 \mathrm{~L} / \mathrm{min}, \geq 45$ to $<52 \mathrm{~L} / \mathrm{min}, \geq 52$ to $<$ $56 \mathrm{~L} / \mathrm{min}$, and $\geq 56$ to $<60 \mathrm{~L} / \mathrm{min}$ ), with approximately the same number of participants within each quintile. Safety was assessed through adverse events (AEs) evaluation.

\section{Assessments}

PIFR was assessed at screening, randomization, and at the end of the study using In-Check ${ }^{\mathrm{TM}}$ DIAL (Alliance Tech Medical, Inc., Granbury, Texas) with resistance set to Diskus as well as HandiHaler. The relationship between Diskus and HandiHaler resistance was estimated using a multiple regression prediction model. ${ }^{13}$ Patients were instructed to exhale completely, place the mouthpiece of the device into their mouths, and inhale forcefully and as deeply as possible to quantify the PIFR; final values were recorded as the maximum of 3 sequential measurements.

Efficacy was assessed via pulmonary function tests, including trough and peak $\mathrm{FEV}_{1}, \mathrm{FVC}$, and trough IC measurements using spirometry at baseline and/or peak on Days 1 and 29. Rescue albuterol medication use was also assessed.

\section{Statistical Analyses}

Sample Size

We planned to enroll approximately 200 patients ( $\mathrm{n}=$ 100 patients/group) to ensure 150 evaluable patients, assuming a withdrawal rate $\leq 25 \%$ and assigned in a 1:1 ratio to revefenacin or tiotropium. The study had $\geq 90 \%$ power to detect a difference between revefenacin and tiotropium treatments $\geq 80 \mathrm{~mL}$ (assuming standard deviation $[S D]=250 \mathrm{~mL}$, a model $\mathrm{R}^{2}$ of 0.65 , and a 2 -sided $5 \%$ significance level) in change from baseline

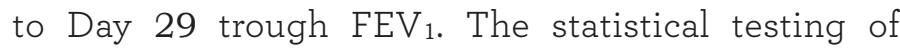
hypotheses was conducted in a sequential manner starting with trough $\mathrm{FEV}_{1}$. If the primary endpoint was not statistically significant, all endpoints were declared nonsignificant. The results are reported as point estimates with $95 \%$ confidence interval (CI).

\section{Efficacy}

The primary endpoint of trough $\mathrm{FEV}_{1}$ was measured as a change from baseline after the 28th dose on Day 29 in the intent-to-treat (ITT) population and patients with evaluable $\mathrm{FEV}_{1}$ measurements. An analysis of covariance (ANCOVA) model was used to evaluate the difference between revefenacin and tiotropium treatments. Treatment group, maximum inspiratory pressure at baseline, ipratropium reversibility, smoking status, concomitant LABA use, sex, age $<65$ years, supplemental oxygen use, baseline PIFR, and center and baseline $\mathrm{FEV}_{1}$ with interaction terms were incorporated as covariates using the ITT population.

Secondary endpoints of trough FVC and IC and peak $\mathrm{FEV}_{1}$ and $\mathrm{FVC}$ were assessed via an approach similar to that used for the primary endpoint.

\section{Results}

\section{Study Population}

This trial was conducted at 38 study sites in the United States between March and November 2017. Of 215 patients who were randomized and received treatment, 8 were excluded from analyses due to suspected misconduct at 1 study site; therefore, 207 patients were included in the safety analysis set (Figure 1). Overall, 206 patients were included in the efficacy analyses as 1 patient did not have efficacy data available.

Patient demographics and baseline characteristics are summarized in Table 1 . Overall, the study population had severe disease, as reflected by mean (SD) percent predicted $\mathrm{FEV}_{1}\left(37 \%\right.$ [15.6\%]) and baseline $\mathrm{FEV}_{1}$ 


\section{Figure 1. Patient Disposition}

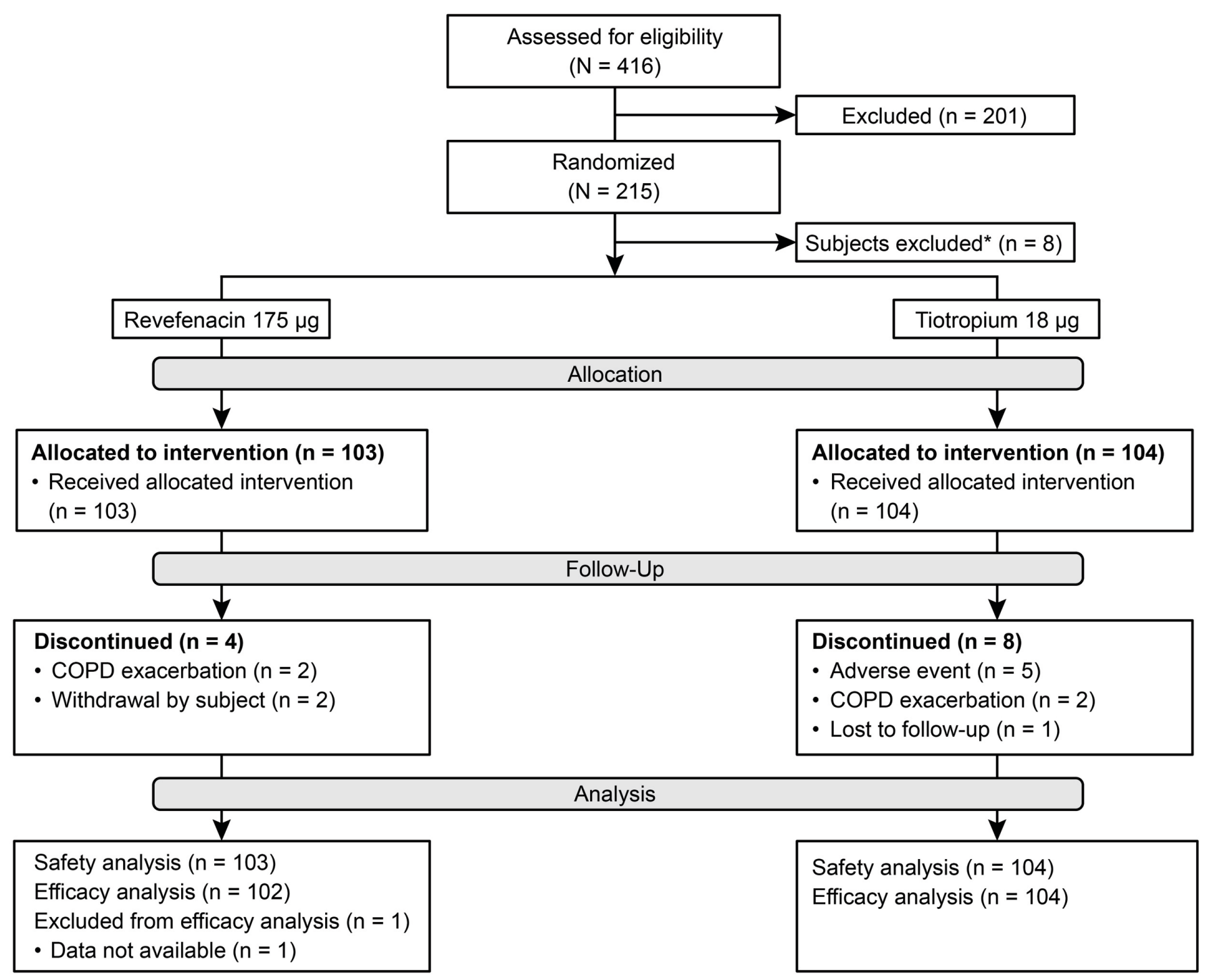

*Eight participants completed the treatment but were not included in the analyses because of suspected misconduct at one site.

$\mathrm{COPD}=$ chronic obstructive pulmonary disease

(0.92 [0.455] L). There were noted differences in baseline lung function (FEV, FVC, IC) across the airflow limitation categories; however, baseline PIFR values were similar between the 2 subgroups.

\section{Efficacy Outcomes}

In the ITT population, revefenacin treatment produced numerically greater improvements from baseline in trough $\mathrm{FEV}_{1}$ versus tiotropium; however, the least squares (LS) mean difference was not statistically significant (Table 2). In patients with $\mathrm{FEV}_{1}<50 \%$ predicted (78\% of ITT population), revefenacin produced a greater change in trough $\mathrm{FEV}_{1}$ than tiotropium with LS mean difference of 49.1 (SD, 21.8; 95\% CI, 6.3-91.9) $\mathrm{mL}$ (Table 2). The likelihood of $>80 \mathrm{~mL}$ change from baseline in trough $\mathrm{FEV}_{1}$ at Day 29 favored revefenacin with an odds ratio of 1.95 (95\% CI, 1.03-3.68). The effect was driven by patients with $\mathrm{FEV}_{1}<50 \%$ predicted, with an odds ratio of 3.57 (95\% CI, 1.66-7.69). More patients achieved $>100 \mathrm{~mL}$ change from baseline in trough $\mathrm{FEV}_{1}$ with revefenacin than tiotropium in ITT (37 [41.6\%] versus 31 [34.4\%]) 


\section{Table 1. Baseline Demographics and Clinical Characteristics}

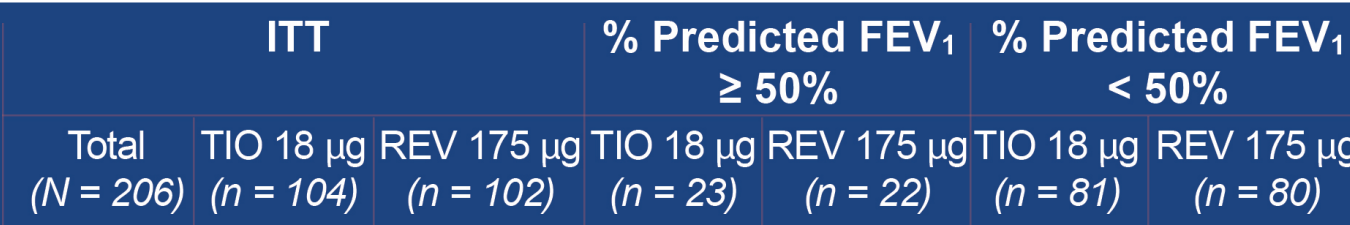

\begin{tabular}{|c|c|c|c|c|c|c|c|}
\hline \multicolumn{8}{|l|}{ Age } \\
\hline Years, mean (SD) & $65.1(8.1)$ & $65.1(8.4)$ & $65.1(7.9)$ & $63.3(8.3)$ & $65.9(9.3)$ & $65.6(8.4)$ & $64.9(7.6)$ \\
\hline$\geq 65$ years, $\mathrm{n}(\%)$ & $102(49.5)$ & $51(49.0)$ & $51(50.0)$ & $9(39.1)$ & $11(50.0)$ & $42(51.9)$ & $40(50.0)$ \\
\hline \multicolumn{8}{|l|}{ Sex, n (\%) } \\
\hline Male & $124(60.2)$ & $64(61.5)$ & $60(58.8)$ & $15(65.2)$ & $10(45.5)$ & $49(60.5)$ & $50(62.5)$ \\
\hline Female & $82(39.8)$ & $40(38.5)$ & $42(41.2)$ & $8(34.8)$ & $12(54.5)$ & $32(39.5)$ & $30(37.5)$ \\
\hline \multicolumn{8}{|l|}{ Race, $\mathrm{n}(\%)$} \\
\hline White & $185(89.8)$ & 95 (91.3) & $90(88.2)$ & $21(91.3)$ & 20 (90.9) & 74 (91.4) & $70(87.5)$ \\
\hline Current Smokers, n (\%) & $96(46.6)$ & $50(48.1)$ & $46(45.1)$ & $15(65.2)$ & $12(54.5)$ & $35(43.2)$ & $34(42.5)$ \\
\hline Concurrent ICS/LABA Users, n (\%) & $111(53.9)$ & $57(54.8)$ & $54(52.9)$ & $9(39.1)$ & $5(22.7)$ & $48(59.3)$ & $49(61.3)$ \\
\hline \multicolumn{8}{|l|}{ Postipratropium } \\
\hline $\mathrm{FEV}_{1} \%$ predicted, mean (SD) & $36.8(15.6)$ & $37.1(15.1)$ & $36.6(16.2)$ & $60.9(6.3)$ & $62.4(8.7)$ & $30.3(8.5)$ & $29.5(8.8)$ \\
\hline $\mathrm{FEV}_{1} / \mathrm{FVC}$ ratio, mean (SD) & $0.42(0.11)$ & $0.43(0.11)$ & $0.42(0.11)$ & $0.57(0.06)$ & $0.56(0.07)$ & $0.38(0.08)$ & $0.38(0.09)$ \\
\hline $\mathbf{F E V}_{\mathbf{1}}, \mathrm{L}$, mean (SD) & $0.9(0.5)$ & $0.9(0.4)$ & $0.9(0.5)$ & $1.5(0.4)$ & $1.5(0.7)$ & $0.8(0.3)$ & $0.7(0.3)$ \\
\hline FVC, L, mean (SD) & $2.2(0.7)$ & $2.2(0.7)$ & $2.2(0.7)$ & $2.8(0.7)$ & $2.8(0.9)$ & $2.1(0.6)$ & $2.0(0.6)$ \\
\hline IC, L, mean (SD) & $1.7(0.6)$ & $1.7(0.6)$ & $1.6(0.6)$ & $2.1(0.6)$ & $2.0(0.7)$ & $1.6(0.6)$ & $1.5(0.5)$ \\
\hline \multicolumn{8}{|l|}{ PIFR } \\
\hline $\mathrm{L} / \mathrm{min}$, mean (SD) & $45(12)$ & $45(11)$ & $45(12)$ & $46(11)$ & $48(9)$ & $45(11)$ & $45(13)$ \\
\hline$<40 \mathrm{~L} / \mathrm{min}, \mathrm{n}(\%)$ & $61(29.6)$ & $30(28.8)$ & $31(30.4)$ & $6(26.1)$ & $3(13.6)$ & $24(29.6)$ & $28(35.0)$ \\
\hline$<50 \mathrm{~L} / \mathrm{min}, \mathrm{n}(\%)$ & $102(49.5)$ & $53(51.0)$ & $49(48.0)$ & $11(47.8)$ & $9(40.9)$ & $42(51.9)$ & $40(50.0)$ \\
\hline $50-60 \mathrm{~L} / \mathrm{min}, \mathrm{n}(\%)$ & $104(50.5)$ & $51(49.0)$ & $53(52.0)$ & $12(52.2)$ & $13(59.1)$ & $39(48.1)$ & $40(50.0)$ \\
\hline mMRC $\geq 2, \mathrm{n}(\%)$ & $154(74.8)$ & 78 (75.0) & $76(74.5)$ & $14(60.9)$ & $13(59.1)$ & $64(79.0)$ & $63(78.8)$ \\
\hline $\begin{array}{l}>1 \text { Exacerbation }{ }^{a} \text { in Prior } \\
\text { Year, } n(\%)\end{array}$ & $19(9.2)$ & $11(10.6)$ & $8(7.8)$ & $1(4.3)$ & $1(4.5)$ & $10(12.3)$ & $7(8.8)$ \\
\hline
\end{tabular}

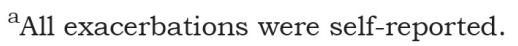

ITT=intent-to-treat; $\mathrm{FEV}_{1}$ =forced expiratory volume in 1 second; TIO=tiotropium; REV=revefenacin; $\mathrm{SD}=$ standard deviation; ICS=inhaled corticosteroid; LABA=long-acting beta2-agonist; FVC=forced vital capacity; IC=inspiratory capacity;

PIFR=peak inspiratory flow capacity; $m M R C=$ modified Medical Research Council (dyspnea scale)

and $\mathrm{FEV}_{1}<50 \%$ predicted $(29[41.4 \%]$ versus 18 [25.7\%]) populations.

Additionally, changes in trough $\mathrm{FEV}_{1}$ were examined by dividing sPIFR into quintiles. In the ITT population, revefenacin treatment produced numerically greater changes in the median trough $\mathrm{FEV}_{1}$ than tiotropium in the $\geq 33$ to $<45 \mathrm{~L} / \mathrm{min}$ quintile of PIFR; no substantial differences were observed in other quintiles (Figure $2 \mathrm{~A})$. In the $\mathrm{FEV}_{1}<50 \%$ predicted population, numerically greater improvements from the baseline in the median trough $\mathrm{FEV}_{1}$ were observed with revefenacin in the $\geq 33$ to $<45 \mathrm{~L} / \mathrm{min}, \geq 45$ to $<52$
$\mathrm{L} / \mathrm{min}$, and $\geq 52$ to $<56 \mathrm{~L} / \mathrm{min}$ quintiles of PIFR; no substantial differences were observed in the $<33$ $\mathrm{L} / \mathrm{min}$ and $\geq 56$ to $<60 \mathrm{~L} / \mathrm{min}$ quintiles (Figure $2 \mathrm{~B}$ ). Substantial variability of $\mathrm{FEV}_{1}$ was observed in all quintiles, especially in the $<33 \mathrm{~L} / \mathrm{min}$ quintile, which demonstrated greater instability than other subgroups.

Revefenacin produced numerically greater improvements in Day 29 trough FVC than tiotropium in the $\mathrm{FEV}_{1}<50 \%$ predicted population (LS mean difference [SD], 103.5 [48.9] mL; 95\% CI, 7.7-199.3 $\mathrm{mL}$ ) and in the ITT population (LS mean difference [SD], 71.5 [43.0] mL; 95\% CI, -12.8 to 155.9 mL; Table 2). 


\section{Table 2. Summary of Trough Efficacy Variables at Day 29}

ITT
TIO $18 \mu \mathrm{g}$
(HandiHaler)
$(n=104)$

REV $175 \mu g$

$(n=104)$
$\%$ Predicted FEV $1<5$

TIO $18 \mu \mathrm{g}$

(HandiHaler)

Change from Baseline Trough FEV $\mathbf{1}, \mathrm{mL}$

\begin{tabular}{|l|r|r|r|r}
\hline Evaluable Patients & 90 & 89 & 70 & 70 \\
\hline LS mean (SE) & $40.9(19.8)$ & $57.9(20.7)$ & $23.2(20.2)$ & $72.3(21.1)$ \\
\hline LS mean difference (SE) & & $17.0(22.4)$ & & $49.1(21.8)$ \\
\hline 95\% CI & & -27.0 to 61.0 & & 6.3 to 91.9 \\
\hline
\end{tabular}

Change from Baseline Trough FVC, $\mathrm{mL}$

\begin{tabular}{|l|r|r|r|r}
\hline Evaluable Patients & 90 & 89 & 70 & 70 \\
\hline LS mean (SE) & $46.9(38.1)$ & $118.4(39.8)$ & $37.9(44.9)$ & $141.4(47.3)$ \\
\hline LS mean difference (SE) & & $71.5(43.0)$ & & $103.5(48.9)$ \\
\hline 95\% CI & & -12.8 to 155.9 & & 7.7 to 199.3 \\
\hline
\end{tabular}

Change from Baseline Trough IC, $\mathrm{mL}$

\begin{tabular}{l|r|r|r|r}
\hline Evaluable Patients & 88 & 82 & 69 & 61 \\
\hline LS mean (SE) & $84.9(41.7)$ & $71.8(43.6)$ & $67.4(41.6)$ & $83.6(43.3)$ \\
\hline LS mean difference (SE) & & $-13.1(47.4)$ & & $16.2(45.4)$ \\
\hline $95 \%$ CI & & -106.0 to 79.9 & & -72.8 to 105.2 \\
\hline
\end{tabular}

ITT=intent to treat; $\mathrm{FEV}_{1}=$ forced expiratory volume in 1 second; TIO=tiotropium; $\mathrm{REV}=$ revefenacin; $\mathrm{LS}=$ least squares; $\mathrm{SE}=$ standard error; $\mathrm{CI}=$ confidence interval; $\mathrm{FVC}=$ forced vital capacity; $\mathrm{IC}=$ inspiratory capacity

More patients achieved $>200 \mathrm{~mL}$ increase in FVC from baseline, which is considered a clinically relevant change, with revefenacin than tiotropium in ITT (34 [38.2\%] versus 29 [32.2\%]) and $\mathrm{FEV}_{1}<50 \%$ predicted (29 [41.4\%] vsersus 20 [28.6\%]) populations. No significant between-group differences were observed in trough IC at Day 29 (Table 2) or peak FEV 1 or FVC on Days 1 and 29 (data not shown). Rescue albuterol use was not different between revefenacin and tiotropium groups (LS mean [standard error], 3.4 [0.42] versus 2.9 [0.41] puffs/day; LS mean difference, 0.6 [0.49] puffs/ day; $95 \%$ CI for LS mean difference, -0.4 to 1.5 puffs/ day).

\section{Safety Outcomes}

Very few AEs were reported for either group, but fewer occurred with revefenacin than with tiotropium (Table 3). Dyspnea and cough were the only treatment-related AEs reported in $>2 \%$ of patients in either group. Patients taking tiotropium reported more treatmentrelated AEs than patients taking revefenacin. The overall rate of antimuscarinic AEs (dry mouth and constipation) was low, but it was even lower in patients treated with revefenacin than with tiotropium. One serious AE (COPD exacerbation) was reported in a patient in the tiotropium group. No serious AEs were reported in patients from the revefenacin group. AEs leading to permanent discontinuation of study drug were reported in $5(4.8 \%)$ patients, and all were in the tiotropium group.

\section{Discussion}

Efficacy of bronchodilators delivered through DPI in patients with COPD and SPIFR is unknown. In one study, a single dose of nebulized arformoterol provided significantly greater increases in FVC and IC (but not $\mathrm{FEV}_{1}$ ) at 2 hours than salmeterol Diskus in patients with COPD and sPIFR (<60 L/min) to Diskus. ${ }^{14}$ In this multicenter, multi-dose randomized trial, we compared the bronchodilator effects of 2 once-daily LAMAs delivered through nebulization versus DPI in patients with COPD and sPIFR.

In the ITT population, the changes from baseline in trough $\mathrm{FEV}_{1}$ and trough FVC were not significantly 


\section{Figure 2. The Median Change from Baseline in Trough Forced Expiratory Volume in One Second in Intent-to-Treat Population (A) and in a Subgroup of Patients with Forced Expiratory Volume in 1 Second $<50 \%$ Predicted (B)}

A

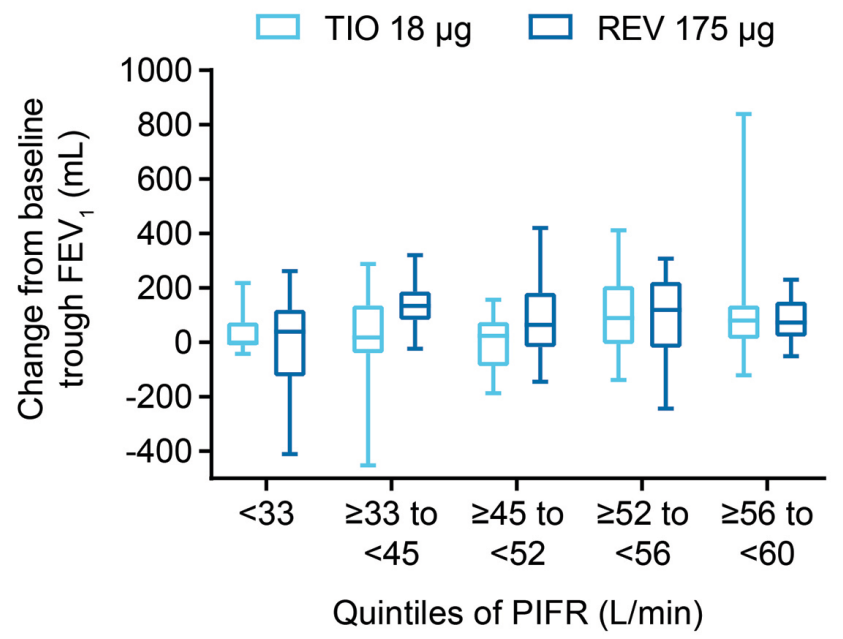

$\begin{array}{cccccc}\text { REV, n } & 20 & 13 & 19 & 16 & 21 \\ \text { TIO, n } & 14 & 21 & 18 & 20 & 17\end{array}$
B

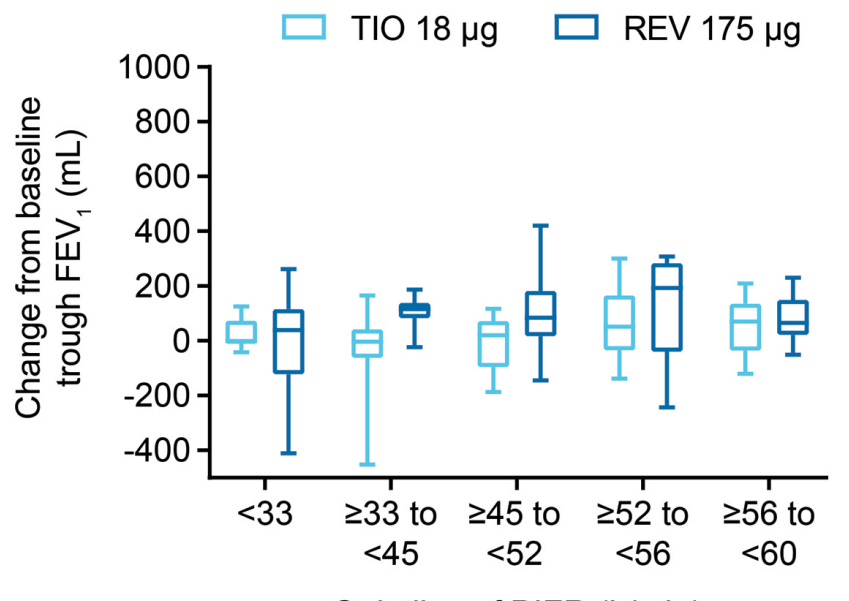

Quintiles of PIFR (L/min)

$\begin{array}{cccccc}\text { REV, n } & 18 & 9 & 14 & 11 & 18 \\ \text { TIO, n } & 11 & 17 & 14 & 14 & 14\end{array}$

The horizontal line inside the box represents the median change from baseline in trough $\mathrm{FEV}_{1}$; ends of the box are the upper and lower quartile; and the 2 lines outside the box extend to the highest and lowest values.

$\mathrm{TIO}=$ tiotropium; $\mathrm{REV}=$ revefenacin $\mathrm{FEV}_{1}=$ forced expiratory volume in 1 second; PIFR=peak inspiratory flow rate

Table 3. Treatment-Emergent Adverse Events Reported in $\geq 1 \%$ of Patients in Any Treatment Group

\begin{tabular}{|c|c|c|}
\hline Adverse Event, n (\%) & $\begin{array}{c}\text { TIO } 18 \mu \mathrm{g} \\
\text { (HandiHaler) } \\
(n=104)\end{array}$ & $\begin{array}{l}\text { REV } 175 \mu g \\
(n=103)\end{array}$ \\
\hline Any Adverse Event & $39(37.5)$ & $12(11.7)$ \\
\hline Headache & $5(4.8)$ & $1(1.0)$ \\
\hline Dyspnea & $4(3.8)$ & $1(1.0)$ \\
\hline Oropharyngeal Pain & $3(2.9)$ & $2(1.9)$ \\
\hline Constipation & $4(3.8)$ & 0 \\
\hline Cough & $4(3.8)$ & 0 \\
\hline Dry Mouth & $1(1.0)$ & $2(1.9)$ \\
\hline Upper Respiratory Tract Infection & $3(2.9)$ & 0 \\
\hline Abdominal Pain Upper & 0 & $2(1.9)$ \\
\hline Back Pain & $2(1.9)$ & 0 \\
\hline
\end{tabular}

TIO=tiotropium; REV=revefenacin different between delivery systems, whereas, in patients with severe to very severe airflow obstruction, revefenacin for nebulization produced numerically greater changes than dry powder tiotropium. Results of a post hoc analysis based on PIFR quintiles suggest a greater benefit from nebulization than DPI in patients with PIFR $\geq 33$ to $<45 \mathrm{~L} / \mathrm{min}$ in the ITT population and PIFR $<56 \mathrm{~L} /$ min in the $\mathrm{FEV}_{1}<50 \%$ predicted subgroup.

Because this is the first multi-dose trial examining patients with COPD and sPIFR, the sample size was calculated based on a projected difference of $80 \mathrm{~mL}$ in change from baseline in trough $\mathrm{FEV}_{1}$ at Day 29 between revefenacin and tiotropium. Revefenacin demonstrated efficacy in two 12week, Phase 3 registration trials (NCT02459080 and NCT02512510), in which revefenacin $175 \mu \mathrm{g}$ improved trough $\mathrm{FEV}_{1}$ at Day 85 by a mean value of $148 \mathrm{~mL}$ versus placebo. ${ }^{15}$ Comparator tiotropium, 
which has been available in the United States since 2003, demonstrated substantial improvements versus placebo in trough $\mathrm{FEV}_{1}$, ranging from $114 \mathrm{~mL}$ at Day 92 during a 13-week trial to $137 \mathrm{~mL}$ following 24 weeks of treatment. ${ }^{16,17}$ Patients in this 4-week trial, however, had more severe airflow obstruction (mean $\mathrm{FEV}_{1}, 37 \%$ versus $55 \%$ predicted) and reported more dyspnea (modified Medical Research Council dyspnea scale score $>2,75 \%$ versus $51 \%$ ) than observed in the registration trials. Two LAMAs were compared in this trial, whereas revefenacin was compared with a placebo in the registration trials.

HandiHaler has the highest internal resistance of the DPIs. ${ }^{7}$ In an in vitro study, an inspiratory flow rate of $40 \mathrm{~L} / \mathrm{min}$ or higher was shown to deliver an optimum dose of the powdered drug. ${ }^{18}$ Because our trial was a pilot study enrolling patients with COPD and sPIFR, we used the optimal PIFR of low-medium resistance DPI Diskus (60 L/min) ${ }^{19,20}$ as the cut-off for sPIFR. Additionally, Diskus resistance is the most frequently used resistance for reporting the prevalence of sPIFR. 4,6,8,14,21,22 The 60-L/min PIFR against the Diskus resistance corresponded with $40-\mathrm{L} / \mathrm{min}$ PIFR against the HandiHaler in this study. ${ }^{13}$ Al-Showair and colleagues reported that a mean PIFR of $58 \mathrm{~L} / \mathrm{min}$ for the Diskus resistance corresponded to $29 \mathrm{~L} / \mathrm{min}$ for the HandiHaler resistance. ${ }^{4}$

Suboptimal PIFR has been demonstrated in $19 \%$ to $78 \%$ of outpatients and $32 \%$ to $52 \%$ of inpatients before discharge from the hospital after treatment for an exacerbation. $6,8,21,22$ In a recent study of 66 patients with COPD, $40 \%$ had sPIFR to prescribed DPIs. ${ }^{9}$ It has been hypothesized that clinical benefit may not be optimum with PIFR $<60 \mathrm{~L} / \mathrm{min}$ against a specific DPI resistance. In the post hoc analysis based on PIFR quintiles in this study, numerically greater change from baseline in the median trough $\mathrm{FEV}_{1}$ was observed with nebulized therapy compared with a DPI in patients with PIFR $\geq 33$ to $<45 \mathrm{~L} / \mathrm{min}$ in the ITT population and $<56 \mathrm{~L} / \mathrm{min}$ in patients with $\mathrm{FEV}_{1}<50 \%$ predicted. For patients in the PIFR quintile $<33 \mathrm{~L} / \mathrm{min}$, inconsistent improvement in trough $\mathrm{FEV}_{1}$ was observed. This is likely due to lack of stability in this group, possibly because of difficulty in measuring inspiratory (lower limit of detection for InCheck DIAL is $20 \mathrm{~L} / \mathrm{min}$ ) and expiratory flow rates in patients with very low PIFR and airflow limitation. Prospective studies are required to further examine the most clinically relevant oPIFR value for use with DPIs. The secondary findings of improved lung function in the subgroup of patients with severe to very severe COPD and $\operatorname{sPIFR}(\geq 33 \mathrm{~L} /$ min to $<56 \mathrm{~L} / \mathrm{min}$ ) are also of interest. These data can be used to calculate an appropriate power effect and sample size for subsequent trials.

There are several study limitations. Because there was no difference in the primary outcome of the study in the ITT population, the findings in patients with $\mathrm{FEV}_{1}<50 \%$ predicted should be interpreted with caution and require investigation in a future study. In addition, patient-reported clinical outcomes were not assessed in this trial and should be evaluated in future studies. Since this was a 4-week trial designed to evaluate the efficacy of revefenacin for nebulization versus dry powder tiotropium, the long-term safety of revefenacin in patients with COPD and sPIFR was not assessed. However, there were no new safety concerns in this patient population.

The 2019 GOLD strategy emphasizes a personalized approach to the treatment of COPD. ${ }^{1}$ Routine measurement of PIFR against the DPI being considered for treatment incorporates the principle of precision medicine. ${ }^{7}$ Patients with sPIFR are predominantly women and have a shorter height, lower percent predicted FVC and IC values, and reduced inspiratory muscle strength. ${ }^{6,8,21-23}$ Lung hyperinflation, which is common in outpatients with COPD and develops with an exacerbation, adversely affects respiratory muscle strength and the ability of patients to generate oPIFR. ${ }^{24,25}$ Prospective studies that compare clinical and physiological outcomes with a DPI and other delivery systems (pressurized metered-dose inhalers, slow mist inhalers, and nebulizers) are needed in patients with COPD who have sPIFR.

\section{Conclusions}

Although revefenacin administered once daily via a standard jet nebulizer produced numerically greater improvements from baseline in trough $\mathrm{FEV}_{1}$ and FVC than dry powder tiotropium, the differences were not significant. Revefenacin produced substantial improvements in lung function among patients with $\mathrm{FEV}_{1}<50 \%$ predicted compared with tiotropium.

\section{Acknowledgements}

This study was funded by Theravance Biopharma, Ireland Limited Inc., (Dublin, Ireland). The authors 
acknowledge Ritu Pathak, PhD, and Autumn Kelly, $\mathrm{MA}$, for medical writing and Frederique H. Evans, MBS, for editorial assistance in the preparation of the manuscript (Ashfield Healthcare Communications, Middletown, Connecticut).

Author Contributions: CNB, EJM, SP, and GDC take responsibility for the conception and design. DAM, $\mathrm{JAO}, \mathrm{CNB}, \mathrm{EJM}, \mathrm{SP}$, and GDC take responsibility for data analysis and interpretation. DAM, JAO, CNB, EJM, SP, and GDC take responsibility for drafting the manuscript for important intellectual content. All authors approve the submitted version of the manuscript and agree to be accountable for the accuracy and integrity of the work.

\section{Declaration of Interest}

DAM has served on advisory boards for AstraZeneca, Boehringer Ingelheim, GlaxoSmithKline plc, Grifols SA, Sunovion Pharmaceuticals Inc., Theravance Biopharma, Inc., and Trevi and is on the speaker's bureau for AstraZeneca, Boehringer Ingelheim, and Sunovion Pharmaceuticals Inc. JAO has served on advisory boards for AstraZeneca, Boehringer Ingelheim, GlaxoSmithKline plc, Mylan Inc, Reckitt Benckiser Group plc, Sunovion Pharmaceuticals Inc., and Theravance Biopharma, Inc. EJM and GDC are employees of Theravance Biopharma US, Inc. CNB and SP were employees of Theravance Biopharma US, Inc. at the time this study was conducted. 


\section{References}

1. Global Initiative for Chronic Obstructive Lung Disease. Global strategy for the diagnosis, management, and prevention of chronic obstructive pulmonary disease: 2019 report. GOLD website. https://goldcopd.org/wp-content/uploads/2018/11/ GOLD-2019-v1.6-FINAL-08Nov2018-wms.pdf.

Published 2018. Accessed December 5, 2018.

2. Tashkin DP. A review of nebulized drug delivery in COPD. Int $J$ Chron Obstruct Pulmon Dis. 2016;11(1):2585-2596. doi: https://doi.org/10.2147/COPD.S114034

3. Muralidharan P, Hayes D, Jr., Mansour HM. Dry powder inhalers in COPD, lung inflammation and pulmonary infections. Expert Opin Drug Deliv. 2015;12(6):947-962.

doi: https://doi.org/10.1517/17425247.2015.977783

4. Al-Showair RA, Tarsin WY, Assi KH, Pearson SB, Chrystyn H. Can all patients with COPD use the correct inhalation flow with all inhalers and does training help? Respir Med. 2007;101(11):23952401. doi: https://doi.org/10.1016/j.rmed.2007.06.008

5. Atkins PJ. Dry powder inhalers: an overview. Respir Care. 2005;50(10):1304-1312.

6. Janssens W, VandenBrande P, Hardeman E, et al. Inspiratory flow rates at different levels of resistance in elderly COPD patients. Eur Respir J. 2008;31(1):78-83.

doi: https://doi.org/10.1183/09031936.00024807

7. Mahler DA. Peak inspiratory flow rate as a criterion for dry powder inhaler use in chronic obstructive pulmonary disease. Ann Am Thorac Soc. 2017;14(7):1103-1107.

doi: https://doi.org/10.1513/AnnalsATS.201702-156PS

8. Mahler DA, Waterman LA, Gifford AH. Prevalence and COPD phenotype for a suboptimal peak inspiratory flow rate against the simulated resistance of the Diskus(R) dry powder inhaler. $J$ Aerosol Med Pulm Drug Deliv. 2013;26(3):174-179.

doi: https://doi.org/10.1089/jamp.2012.0987

9. Ghosh S, Pleasants RA, Ohar JA, Donohue JF, Drummond MB. Prevalence and factors associated with suboptimal peak inspiratory flow rates in COPD. Int J Chron Obstruct Pulmon Dis. 2019;14:585-595. doi: https://doi.org/10.2147/COPD.S 195438

10. International Conference on Harmonisation. International Conference on Harmonisation of Technical Requirements for Registration of Pharmaceuticals for Human Use (ICH). Integrated addendum to ICH harmonised guideline: Guideline for good clinical practice E6 (R2). International Conference on Harmonisation website. http://www.ich.org/fileadmin/Public Web_Site/ICH_Products/Guidelines/Efficacy/E6/E6_R2__ Addendum_Step2.pdf

Published June 2015. Accessed September 2019.
11. World Medical Association. World Medical Association Declaration of Helsinki: ethical principles for medical research involving human subjects. JAMA. 2013;310(20):2191-2194. doi: https://doi.org/10.1001/jama.2013.281053

12. Maleki-Yazdi MR, Kaelin T, Richard N, Zvarich M, Church A. Efficacy and safety of umeclidinium/vilanterol $62.5 / 25 \mathrm{mcg}$ and tiotropium $18 \mathrm{mcg}$ in chronic obstructive pulmonary disease: Results of a 24-week, randomized, controlled trial. Respir Med. 2014;108(12):1752-1760.

doi: https://doi.org/10.1016/j.rmed.2014.10.002

13. Barnes C, Mahler DA, Ohar JA, Crater G. Defining repeatability limits for measuring peak inspiratory flow rates in clinical trials. Am J Respir Care Med. 2019:A1130. doi: https://doi.org/10.1164 /ajrccm-conference.2019.199.1_MeetingAbstracts.A1130

14. Mahler DA, Waterman LA, Ward J, Gifford AH. Comparison of dry powder versus nebulized beta-agonist in patients with COPD who have suboptimal peak inspiratory flow rate. $J$ Aerosol Med Pulm Drug Deliv. 2014;27(2):103-109. doi: https://doi.org/10.1089/jamp.2013.1038

15. Ferguson GT, Feldman G, Pudi KK, et al. Improvements in lung function with revefenacin for nebulization in the treatment of patients with moderate to very severe COPD: Results from two replicate phase III clinical trials. Chronic Obstr Pulm Dis. 2019;6(2). doi: https://doi.org/10.15326/jcopdf.6.2.2018.0152

16. Casaburi R, Briggs DD, Jr., Donohue JF, Serby CW, Menjoge SS, Witek TJ, Jr. The spirometric efficacy of once-daily dosing with tiotropium in stable COPD: a 13-week multicenter trial. The US Tiotropium Study Group. Chest. 2000;118(5):1294-1302. doi: https://doi.org/10.1378/chest.118.5.1294

17. Donohue JF, van Noord JA, Bateman ED, et al. A 6-month, placebo-controlled study comparing lung function and health status changes in COPD patients treated with tiotropium or salmeterol. Chest. 2002;122(1):47-55. doi: https://doi.org/10.1378/chest.122.1.47

18. Chodosh S, Flanders JS, Kesten S, Serby CW, Hochrainer D, Witek TJ, Jr. Effective delivery of particles with the HandiHaler dry powder inhalation system over a range of chronic obstructive pulmonary disease severity. J Aerosol Med. 2001;14(3):309-315. doi: https://doi.org/10.1089/089426801316970268

19. Ghosh S, Ohar JA, Drummond MB. Peak inspiratory flow rate in chronic obstructive pulmonary disease: implications for dry powder inhalers. J Aerosol Med Pulm Drug Deliv. 2017;30(6):381387. doi: https://doi.org/10.1089/jamp.2017.1416

20. Sanders MJ. Guiding inspiratory flow: development of the InCheck DIAL G16, a tool for improving inhaler technique. Pulm Med. 2017;2017:1495867. doi: https://doi.org/10.1155/2017/1495867 
21. Loh CH, Peters SP, Lovings TM, Ohar JA. Suboptimal inspiratory flow rates are associated with chronic obstructive pulmonary disease and all-cause readmissions. Ann Am Thorac Soc. 2017;14(8):1305-1311.

doi: https://doi.org/10.1513/AnnalsATS.201611-903OC

22. Sharma G, Mahler DA, Mayorga VM, Deering KL, Harshaw $\mathrm{O}$, Ganapathy V. Prevalence of low peak inspiratory flow rate at discharge in patients hospitalized for COPD exacerbation. Chronic Obstr Pulm Dis. 2017;4(3):217-224.

doi: https://doi.org/10.15326/jcopdf.4.3.2017.0183

23. Malmberg LP, Rytila P, Happonen P, Haahtela T. Inspiratory flows through dry powder inhaler in chronic obstructive pulmonary disease: age and gender rather than severity matters. Int J Chron Obstruct Pulmon Dis. 2010;5:257-262. doi: https://doi.org/10.2147/COPD.S11474

24. Broeders MEAC, Molema J, Hop WCJ, Vermue NA, Folgering HTM. The course of inhalation profiles during an exacerbation of obstructive lung disease. Respir Med. 2004;98(12):1173-1179. doi: https://doi.org/10.1016/j.rmed.2004.04.010

25. van der Palen J. Peak inspiratory flow through Diskus and Turbuhaler, measured by means of a peak inspiratory flow meter (In-Check DIAL ${ }^{\circledR}$ ). Respir Med. 2003;97(3):285-289.

doi: https://doi.org/10.1053/rmed.2003.1289 